\title{
Design and Experimental Study on the Automatic Speed Control System of a Pneumatic Submersible Pump
}

\author{
Xueyun Ruan ${ }^{1, *}$, Qiangqiang $\mathrm{Ma}^{1}$, Xiangxin $\mathrm{Lv}^{1}$, Dandan Liu ${ }^{1}$ and Bin Zhang ${ }^{2}$ \\ ${ }^{1}$ School of Mechanical Engineering, Anhui University of Science and Technology, Huainan 232000,China, \\ ${ }^{2}$ Department of Mining and Mineral Resources Engineering, Southern Illinois University Carbondale, Carbondale, Illinois 62901, USA
}

Received 28 January 2017; Accepted 8 August 2017

\begin{abstract}
Pneumatic submersible pump is a new type of drainage tool in farmland irrigation. The water supply at the pumping end of the submersible pump is sporadic with frequent no-load operation given the low water levels in most rural canals during summer. The change in water flow and pressure directly causes high turbine speed and thus leads to the runaway speed phenomenon, which seriously affects operational safety. A pneumatic control system based on metering-out control was proposed to prevent high turbine speed and minimize the consumption of the pneumatic submersible pump in irrigation and drainage. First, the pneumatic liquid level control system was designed to automatically adjust the pressure and flow of the submersible pump under no-load and load conditions. Second, the stability of the system was simulated by Advanced Modeling and Simulation Environment for Systems Engineering (AMESim), and the coupling relationship among turbine speed, inlet pressure, and flow rate was discussed with different metering-out flows. Finally, comparative experiments were conducted for verification. Simulation and experimental results show that under the no-load condition, when the inlet pressure reaches $0.2 \mathrm{Mpa}$, the rotating speed of the pneumatic submersible pump increases with the inlet pressure, and when the inlet pressure reaches $0.4 \mathrm{Mpa}$, the rotating speed of the pneumatic submersible pump remains approximately unchanged. When the outlet flow increases, the rotating speed of the pneumatic submersible pump also increases gradually; when the outlet flow is equal to the inlet flow, the rotating speed remains stable; when the inlet pressure is higher than $0.4 \mathrm{Mpa}$ and the outflow flow is smaller than $18 \mathrm{~m}^{3} / \mathrm{h}$, the turbine speed can be less than 12000 $\mathrm{r} / \mathrm{min}$, which is lower than the critical runaway speed. Thus, the total power loss is not reduced. The control system solves the problem of runaway speed and realizes automatic speed control of the pneumatic submersible pump under the no-load condition. The proposed method provides wide application prospects and is suitable for discontinuous irrigation and drainage operation of rural canals.
\end{abstract}

Keywords: Pneumatic submersible pump; Metering-out control; No load; Pneumatic-liquid level control system; Runaway speed

\section{Introduction}

In modern agricultural production, the pneumatic submersible pump has become a new type of drainage tool in farmland irrigation due to its turbine rotating structure and high pneumatic efficiency.It is also safe and environmentally friendly. A pneumatic submersible pump helps farmers in irrigation. However, the water supply at the pumping end of the submersible pump is sporadic given the low water levels in most rural canals during summer. When the pneumatic submersible pump operates with no load, the pump spindle easily produces the runaway phenomenon, which can cause the working turbine to break. High-speed rotating pieces may fly out through the pump body and cause great harm to personal and equipment [1-2]. Thus, controlling the runaway phenomenon is a problem that requires an urgent solution in agricultural safety production.

At present, the automatic speed limiting device of the pneumatic submersible pump, which was studied by Malcolm J. Brandt in the U.S., mainly acts on the open-

\footnotetext{
*E-mail address: ruanxueyun@163.com

ISSN: 1791-2377 @ 2017 Eastern Macedonia and Thrace Institute of Technology. All rights reserved.

doi:10.25103/jestr.104.04
}

phase failure by using the current induction principle or the temperature sensor. However, this type of sensor is easily affected by environmental interference signals and temperature drift of the preamplifier. Thus, this type of sensor is unsuitable for operation in a severe field environment [3].

Researchers have conducted numerous studies on different automatic speed limiting devices on existing pneumatic submersible pumps. However, they cannot accurately describe the quantitative relationship between the pressure and flow and the rotating speed of the spindle given the different structure designs and control principles. Such relationship is crucial to the speed limit design of the pneumatic submersible pump.

The pneumatic liquid level control system, which can automatically adjust the pressure and flow of the submersible pump under no-load and load conditions based on the metering-out control principle, is designed. Then, an analog simulation on the stability of the system is conducted by using Advanced Modeling and Simulation Environment for Systems Engineering (AMESim). The coupling relationship between the turbine speed and the inlet pressure and flow rate is studied by adjusting the outlet flow to provide a theoretical basis for the control system design of the automatic-speed-limit pneumatic submersible pump 


\section{State of the art}

Researchers have conducted numerous studies on the speed limiting device of the submersible pump[4-5].Kurteev studied the duration of the continuous operation of a pneumatic diaphragm pump, analyzed the design and material of the diaphragm, and obtained the calculation formula for the degree of diaphragm deformation. However, he did not conduct detailed research on the speed limit of the diaphragm pump[6].Rodriguez studied a water-glycerol double-tank water storage system, simulated the characteristics of the fluid of the high-temperature molten salt system, and proved that the pneumatic pump is feasible for pumping. He stated that a certain relationship exists between the pumping speed and some variables. However, he did not consider the control of the pumping speed [7]. Banjar expounded the influence of the performance of an electric submersible pump on oil viscosity, developed a computational fluid dynamics (CFD) simulation based on the shear stress transport (SST) turbulence model, and compared the results with experimental findings, concluding that circulating flow appears at the rear of the impeller blade if the viscosity increases[8].Brook introduced a hydraulic submersible pump, which requires two new constraints of the pressure and power of the system in multi-phase flow simulation[9]. Marsis presented a detailed CFD model of an electric submersible pump hybrid multilevel dust collector and studied the effect of geometric change on the thrust curve but did not conduct targeted research on the speed control system [10]. Rabbi introduced the modeling and analysis of the interior permanent magnet motor drive system in an electric pump. The rotor experienced no slip power loss in the steady state, but the motor possibly had light leakage, it burns easily, and the rotating speed of the rotor could not be controlled [11].Zheng Gongliang proposed to add the automatic control mechanical structure of a pneumatic submersible pump on the main shaft and developed the design principle of the control structure, addressing the limited rotating speed of the main shaft [12]. Liang Haizhen identified the performance parameters that affect the working characteristics of the main shaft speed, presented a calculation method for the main design parameters of the key part impeller, and provided a theoretical basis for the design of the safety speed protection device of the pneumatic pump [13].

These references mainly focused on the structural optimization of the pump and the industrial application. Less research has been conducted on the turbine speed characteristics of a pneumatic pump, and almost no research on the runaway speed phenomenon is available. This study designs a pneumatic liquid level control system that can automatically adjust the pressure and flow of the submersible pump under no-load and load conditions. This study also conducts analog simulation and experimental research on the stability of the system through AMESim based on the metering-out control principle.

The remainder of this study is organized as follows: Section 3 describes the structure design and working principle of a pneumatic submersible pump, presents the designs of the pneumatic liquid level control system, which can adjust the rotating speed of the submersible pump; and verifies these designs through experiments.Section 4 provides an analysis of the pressure and flow characteristics of the pneumatic model through AMESim and a conclusion on the influence of the changes in inlet pressure and flow on the rotating speed. Section 5 summarizes the conclusions.

\section{Methodology}

\subsection{Structural Design and Working Principle of the Pneumatic Pump}

Fig. 1 presents the structural diagram of the turbine-type pneumatic submersible pump. Its power source adopts the compressed air method. The air, which is pollution free and recyclable, can be directly obtained from the atmosphere without matching or processing. From the perspective of the prime power medium, the turbine pump is economical and environmentally friendly. The power of the turbine pump is mainly composed of the turbine and impeller.The mechanical transmission consists of the pump shaft, bearing support, upper bearing, turbine foundation, lower bearing, and the framework oil seal. The intake nozzle propels the turbine to drive the pump shaft to work at high speed, and the rotation of the pump shaft drives the impeller to work[14].The centrifugal impeller realizes the drainage function of the pneumatic pump according to the centrifugal dewatering principle.

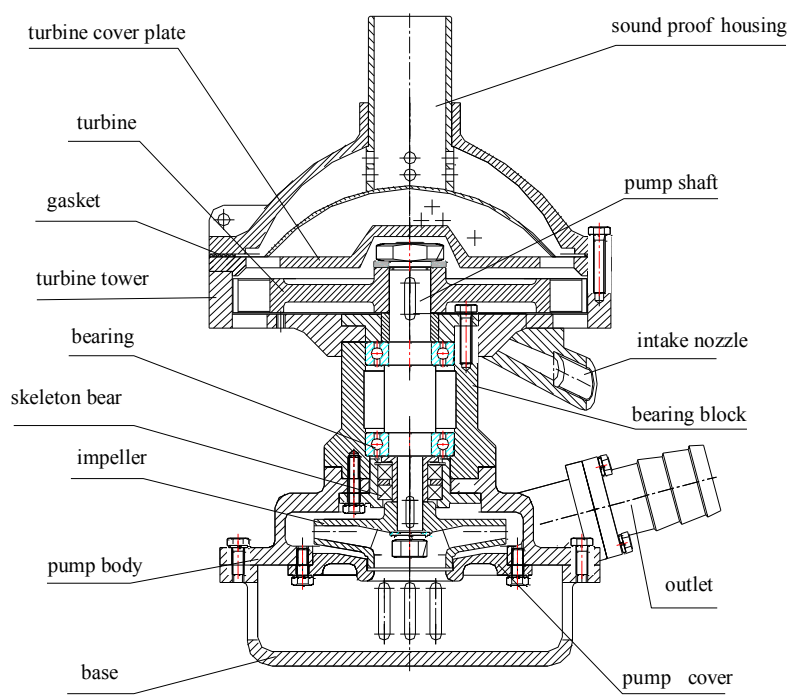

Fig.1. Structural diagram of the turbine-type pneumatic submersible pump.

\subsection{Design of the Pneumatic Control System}

To solve the runaway phenomenon during the drainage work of the pneumatic submersible pump, the metering-out control system is adopted to adjust the rotating speed of the pneumatic turbine-type motor with no load. The rotating speed of the turbine is reduced by using this method [15-16]. The study mainly uses the signals provided by the liquid level detection sensor to allow the electromagnetic valve to work and then realize the automatic speed limit of the pneumatic submersible pump. The electricity-gas control system in the study is composed of a liquid level sensor, a relay module, an electromagnetic valve, and a throttle valve, as shown in Fig. 2. The pneumatic control mainly consists of a pressure gauge, a pneumatic motor (the same as the turbinein Fig. 1), a fixed pressure reducing valve, a switch valve, and a throttle valve [17].The turbine-type pneumatic submersible pump achieves the automatic speed limit through the directional change of electromagnetic valve 1 at the inlet (the same below) and electromagnetic valve 2 at the exhaust outlet (the same below). 


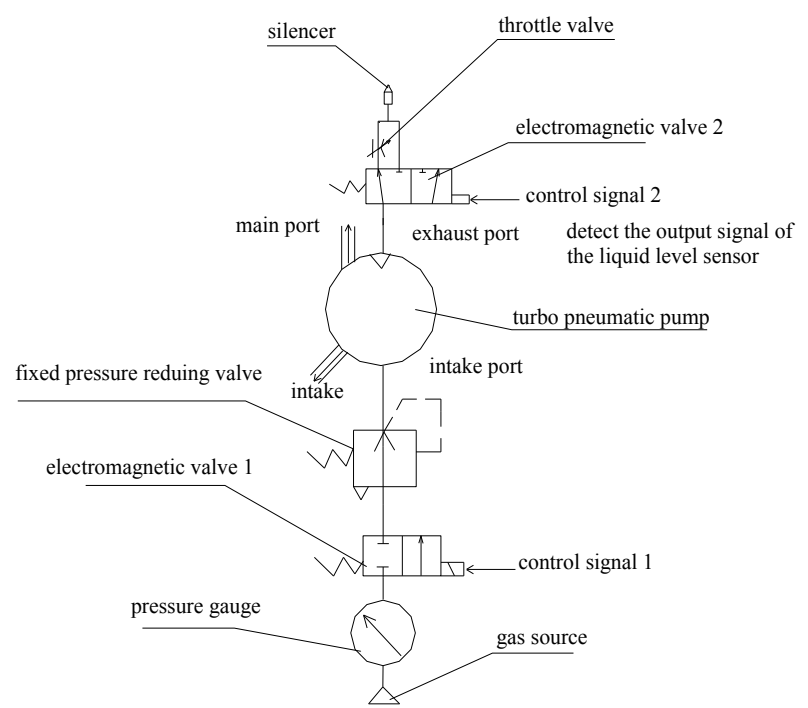

Fig. 2. Schematic of the pneumatic control principle.

The pneumatic control device is made up of an air source, a pressure gauge, a switch valve, a fixed pressure reducing valve, an electromagnetic valve, a throttle valve, and a pneumatic motor. When the liquid level sensor detects the water level, the pneumatic submersible pump operates normally. When the liquid level sensor fails to detect the water level, it passes the control signal to electromagnetic valve 2 to control it to change the direction. At this time, the air at the outlet of the turbine-type pneumatic motor will be exhausted through the throttle valve first and then the muffler, thus realizing the objective of metering-out control [18]. In the no-load state (without water), the liquid level sensor outputs the control signal. When it operates on the set time, electromagnetic valve 1 changes the direction, the pneumatic motor stops operation immediately, and the pump stops working. When the liquid level sensor detects the water level again, the control signal output by the liquid level sensor controls electromagnetic valve 1 to change the direction. Then, the pneumatic motor begins to work immediately. Fig. 3 presents flowchart of the automaticspeed-limit pneumatic submersible pump control system.

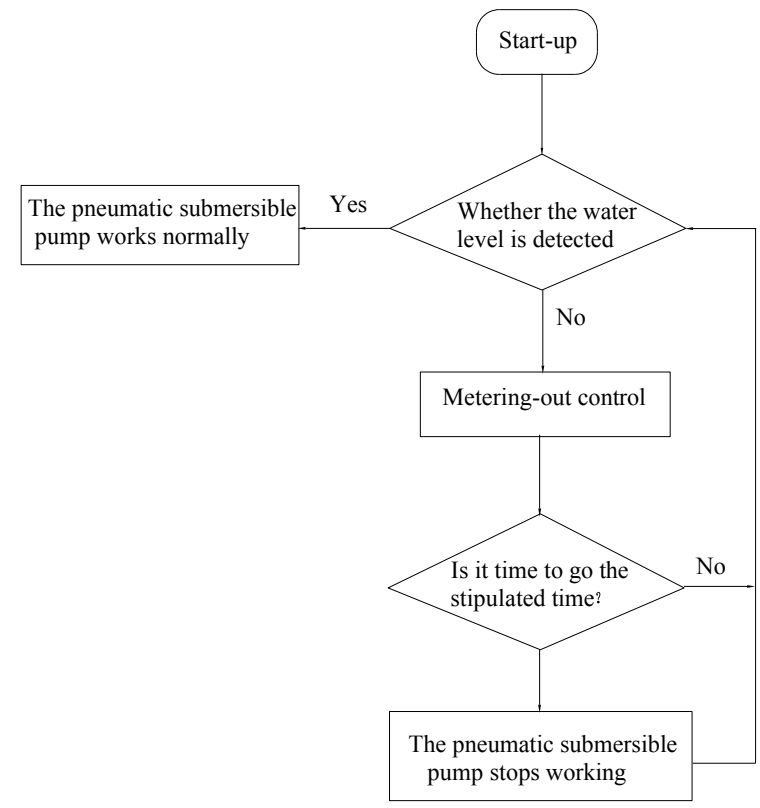

Fig.3. Flowchart of the automatic-speed-limit pneumatic submersible pump control system.
The control system consists of a pneumatic control system, a liquid level control system, and a pneumatic submersible pump. It not only solves the automatic speed limit under the no-load condition but also stops working automatically at the preset time and begins to work automatically after re-detecting the load.

\subsection{Design of the Liquid Control System}

In this study, the liquid level sensor transmits the signal by using the water level with and without load. The intelligent liquid level sensor uses the induction capacitance of water to detect the location of the liquid and converts the changing electricity into the electrical signal to control the on-off function of the electromagnetic valve. The relay receives the signal and passes it to the electromagnetic valve. The changeover switch of the electromagnetic valve is used to control the automatic speed limit of the submersible pump.

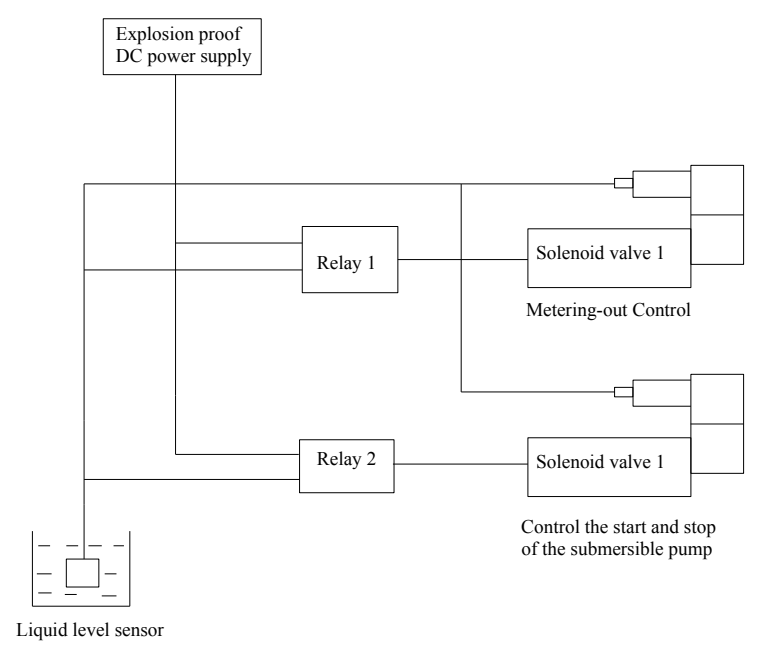

Fig. 4. Wiring diagram of the liquid level control system.

Fig. 4 presents wiring diagram of the liquid level control system. The working principle of the liquid level control system is as follows: the liquid level sensor outputs the high level signal when detecting the water level. The relay receives the signal and transmits it to the electromagnetic valve. The pneumatic turbine submersible pump performs the drainage work normally. The liquid level sensor outputs the low level signal when it cannot detect the water level. At this time, relay 2 controls electromagnetic valve 2 to change the direction immediately to realize the automatic speed limit of the pneumatic submersible pump and avoid the runaway speed phenomenon of the turbine. Then, relay 1 begins to time. After $300 \mathrm{~s}$ (it can be set automatically), if the liquid level sensor does not detect the signal, then electromagnetic valve 1 is controlled to change the direction to stop the pneumatic turbine submersible pump from working. When the liquid level sensor detects the water level again, the pneumatic turbine submersible pump begins the drainage work normally.

\subsection{On-site Simulation Experiment}

Experimental process: As shown in Fig. 5, the liquid level sensor is placed in water at the beginning. The high-pressure gas produced by the air compressor goes from the gas source to the pressure gauge (used to observe and adjust the pressure in the circuit). The gas passes through 
electromagnetic valve 1 and the fixed pressure reducing valve to arrive at the pneumatic motor and enable it to work according to the normal working mode rotation. When the liquid level sensor leaves the water, relay 2 controls electromagnetic valve 2 to change the direction. At this time, the gas on the main gas path is exhausted directly from the throttle valve and the muffler to the atmosphere. The rotating speed of the pneumatic motor is reduced to eliminate the hidden safety issue due to the metering-out control role of the throttle valve. Then, relay 1 begins to time for $300 \mathrm{~s}$. After $300 \mathrm{~s}$, electromagnetic valve 1 changes the direction, and the pneumatic motor stops working; thus, energy saving is achieved. Then, the liquid level sensor is placed in the water again. The pneumatic motor begins to operate normally, starting automatically when detecting the load.

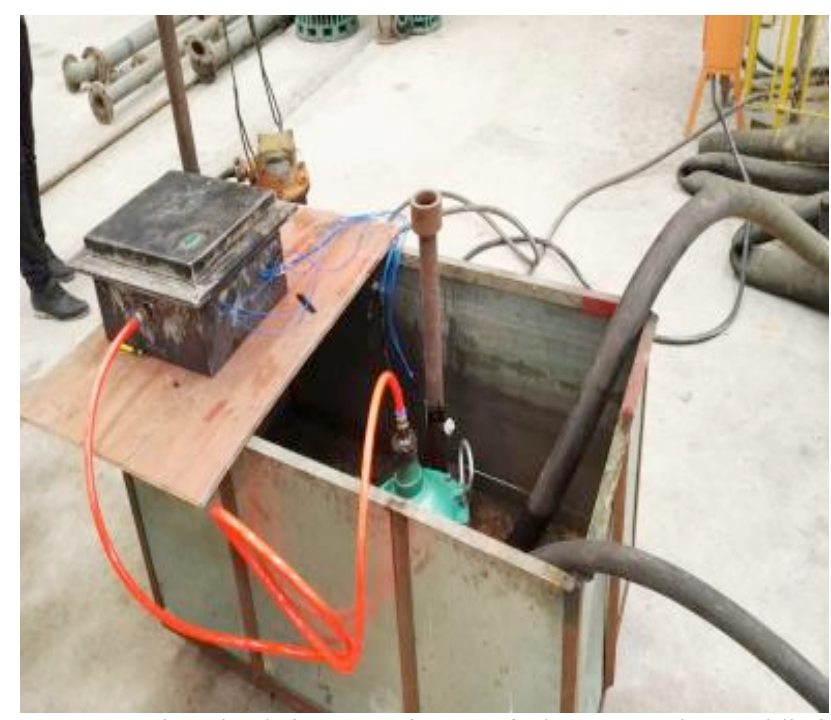

Fig.5. On-site simulation experiment of the automatic-speed-limit pneumatic submersible pump control system.

Table. 1 and Fig. 6 present the on-site experimental data and the changing motor speed of the automatic-speed-limit pneumatic submersible pump control system. Experimental procedure: The air source switch was turned on, the pressure was controlled at 0.7 Mpa, and the switch valve of the control system was opened to enable the motor to rotate. When the liquid level sensor leaves the water, the rotating speed of the motor could be controlled to change within $500 \mathrm{r} / \mathrm{min}$ to $1300 \mathrm{r} / \mathrm{min}$ through the control system device. After $300 \mathrm{~s}$, the rotating speed of the motor was $0 \mathrm{r} / \mathrm{min}$. When the liquid level sensor detected the load again, the rotating speed of the motor changed within $2500 \mathrm{r} / \mathrm{min}$ to $3500 \mathrm{r} / \mathrm{min}$, and the pneumatic motor operated normally.

Table 1.On-site experimental data of the automatic-speedlimit pneumatic submersible pump control system

\begin{tabular}{l|l|l|c}
\hline $\begin{array}{l}\text { Liquid level } \\
\text { sensor with or } \\
\text { without load }\end{array}$ & $\begin{array}{l}\text { Pressure } \\
(\mathrm{Mpa})\end{array}$ & Speed $(\mathrm{r} / \mathrm{min})$ \\
\hline Yes & 0.7 & $\begin{array}{l}2500-3500 \\
0-300 \mathrm{~s} \\
\text { No }\end{array}$ & $\begin{array}{l}300 \mathrm{~s} \text { later } \\
500-1300 \\
0\end{array}$ \\
\hline
\end{tabular}

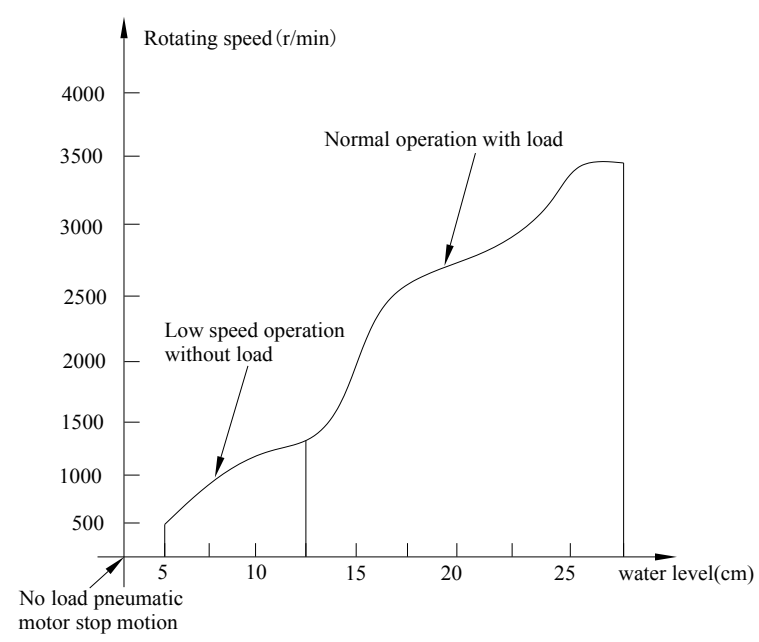

Fig. 6. Changing range of the motor speed, starting from $0.7 \mathrm{Mpa}$.

Conclusion of the experiment: Several experiments show that the automatic speed control system of the pneumatic submersible pump has high reliability. It can automatically realize the speed limit and on-off control of the pneumatic submersible pump through the load determined by the liquid level sensor to achieve the automatic speed limit. The pneumatic submersible pump automatically stops at the preset time and then starts when the load is detected again; thus, runaway prevention, energy saving, and emission reduction are achieved.

\section{Result Analysis and Discussion}

\subsection{Establishment of the Simulation Model}

To accurately describe the influence of the changes in the inlet flow rate and pressure on the rotating speed, The theoretical model is established by AMESim [19-20]. Appropriate components are selected from the existing application libraries of AMESim as follows: signal control library, machine library, air pressure library, and air pressure component design library. A system model is developed according to the designed pneumatic system circuit. Fig. 7 presents the established AMESim simulation model.

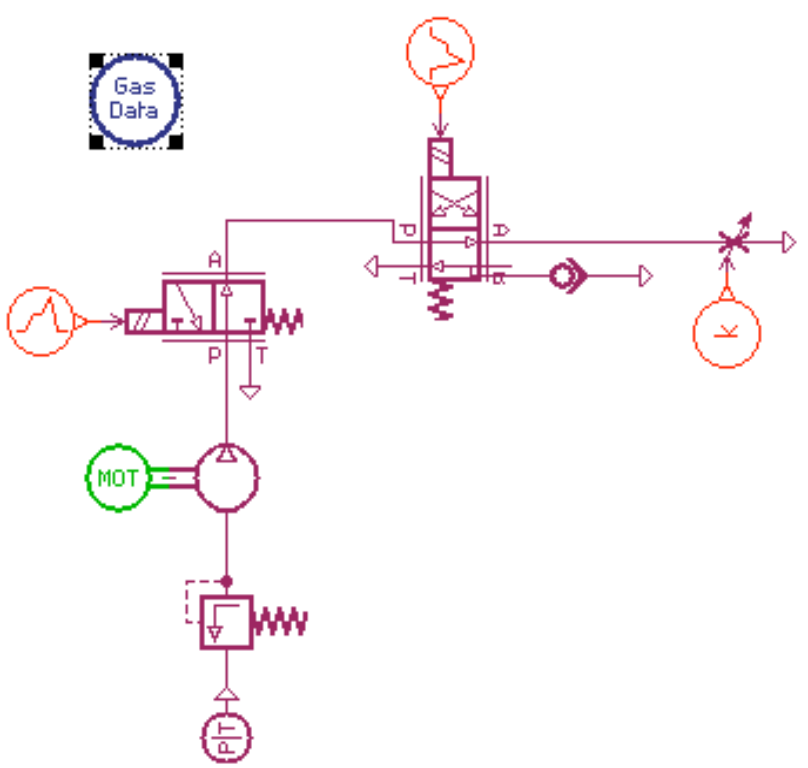

Fig. 7. AMESim model of the pneumatic control system. 
Specific parameters are set for each graphic module in the parameter mode. Only the accurate parameters can be consistent with the actual situation, and the simulation results can be more accurate. The air pressure is set as 0.8 $M p a$, the displacement of the pneumatic pump is set as 20 $\mathrm{m}^{3} / \mathrm{h}$, the pressure of the pressure reducing valve is set as $0.7 \mathrm{Mpa}$, and the inlet pressure of the electromagnetic valve is set as $0.7 \mathrm{Mpa}$.

\subsection{Result Analysis}

The relationship between pressure and flow at the inlet under different outlet flows is analyzed according to the above settings. The dynamic characteristic of the rotating speed of the pneumatic motor is mainly determined by the change in inlet pressure and flow. The simulation time is set as $10 \mathrm{~s}$, and the step length is set as $1 \mathrm{~s}$.

Fig. 8 presents the characteristic curve between the flow rate and pressure at the inlet of the pneumatic motor. When the outlet flow is fixed, the inlet pressure shows a downward trend with the increase in the inlet flow. When the inlet flow is equal to the outlet flow, the pressure tends to be stable. When the inlet pressure is fixed, the outlet flow reduces with the decrease in the inlet flow.

Figs. 9 and 10 show the characteristic curves between turbine speed and inlet pressure and flow. When the inlet pressure of the pneumatic pump reaches $0.2 \mathrm{Mpa}$, the pneumatic pump outputs the rotational speed. The rotating speed increases with the inlet pressure. When the pressure reaches $0.4 \mathrm{Mpa}$, the rotating speed remains approximately unchanged. When the outlet flow increases, the turbine speed increases continuously. When the outlet flow is equal to the inlet flow, the turbine speed reaches the maximum value.

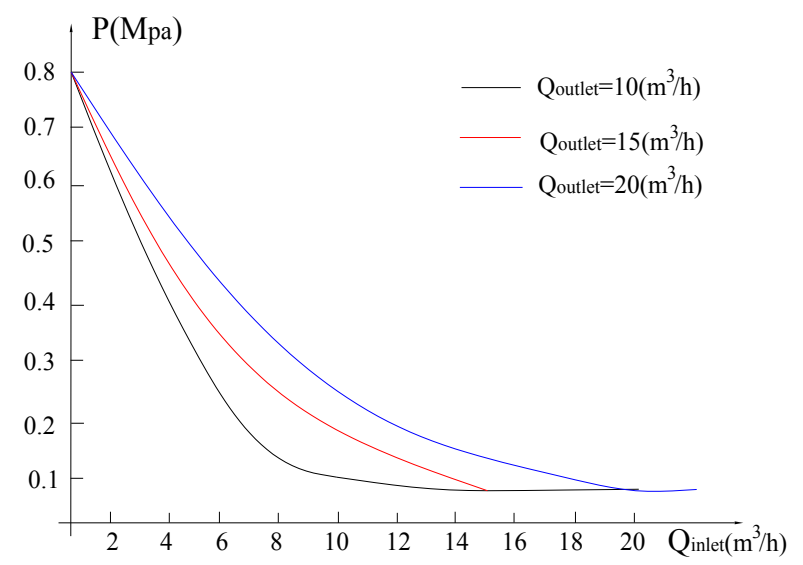

Fig. 8. Characteristic curve between inlet flow and pressure.

\section{Conclusions}

To solve the runaway speed problem of a pneumatic submersible pump with no load and reveal the characteristic relationship between the rotating speed and the inlet flow and pressure, this study analyzed the influencing factors of the high rotating speed of the submersible pump and designed the pneumatic control system and the liquid level control system, which could reduce the rotating speed. Moreover, the influence of the inlet pressure and flow on the rotating speed was analyzed by combining analog simulation and experimental verification. The following conclusions were obtained:

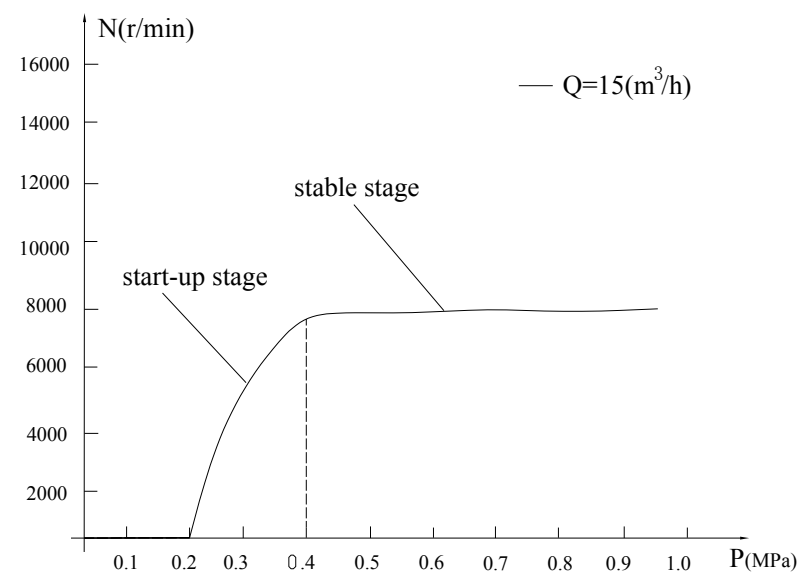

Fig. 9. Characteristic curve between rotating speed and pressure.

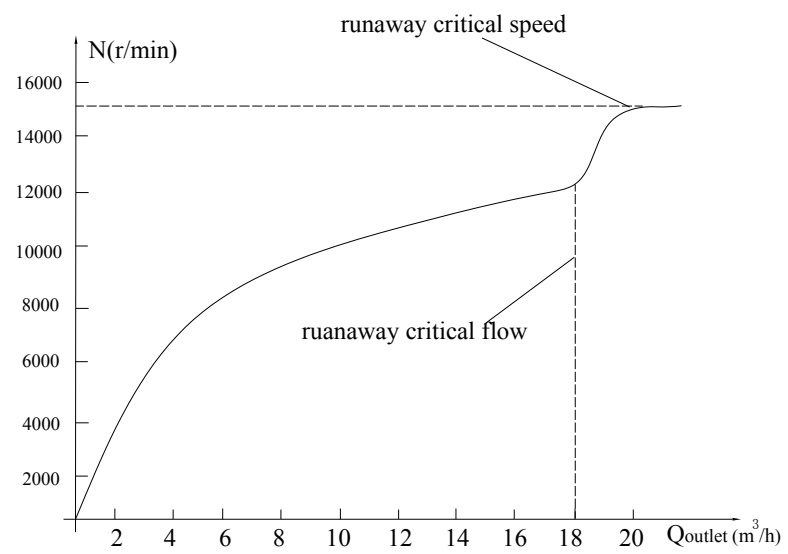

Fig. 10. Characteristic curve between rotating speed and flow.

(1) The outlet flow is the main factor that affects the rotating speed and is the essential cause of the runaway speed phenomenon.

(2) When the outlet flow of the pneumatic submersible pump is constant, the inlet pressure shows a downward trend with the increase in the inlet flow. When the inlet flow is equal to the outlet flow, the pressure tends to stabilize gradually. When the inlet pressure is constant, the outlet flow decreases with the reduction in the inlet flow.

(3) When the inlet pressure is higher than 0.4 Mpa and the outlet flow is less than $18 \mathrm{~m}^{3} / \mathrm{h}$, the turbine speed can be controlled to be lower than $12,000 \mathrm{r} / \mathrm{min}$. Therefore, no risk of runaway speed phenomenon exists.

The study combines theoretical research and simulation experiment to present a new automatic-speed-limit pneumatic submersible pump control system, establishes an AMESim model of the pneumatic control system, and obtains the linear relationship between the inlet flow and pressure and the rotating speed of the main shaft. Therefore, this study demonstrates and promotes the significance of the design of the speed control device of the pneumatic submersible pump. However, the experiments are all based on indoor simulation; thus, some deviations from the actual situation in the field exist. Future studies can combine the 
actual working environment of the submersible pump with the proposed model and provide some revisions, thereby ensuring an accurate understanding of the automatic speed control system of the submersible pump.

\section{Acknowledgements}

This work was supported by Anhui Natural Science Foundation Project of China under the project No. KJ2016A201.
This is an Open Access article distributed under the terms of the Creative Commons Attribution Licence

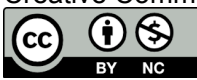

\section{References}

1. Yong Sheng You,Zhi Yong Ma, et al., "Overview of Pneumatic Pump Reversing Mechanism”. Applied Mechanics and Materials, 201(11), 2012, pp.11-14.

2. Zhi Fei Yang,Zhi Yong Ma,et al., "Innovation Design of Pneumatic Pump Reversing Mechanism Aided by Patent Knowledge”. Applied Mechanics and Materials, 202(11), 2012, pp.3-6.

3. Qing Wu Wang., "Research on Safety Performance of Submersible Pump". Colliery Mechanical\&Electrical Technology, 16(2), 2016, pp.52-54.

4. Fei Wang, Xueyun Ruan., "Design of wind turbine submersible pump based on fluid pressure changes preventing over speed". Chinese Hydraulics and Pneumatics. 41(1), 2015, pp.69-71,77.

5. Xiqing Ma, Zhifu Yu, Jian Cui,et.al., "Theoretical analysis of impeller rotate speeds for mine pneumatic pump". Journal of China Coal Society, 30(1), 2005, pp.126-128.

6. Kurteev, V.A., "Diaphragms for Pneumatic Pumps". Chemical and Petroleum Engineering, 47(9), 2011, pp.550-556.

7. Inri Rodriguez., Jesus Cerda., Daniel S. Codd., "Experimental Exploration of a Small Scale Pneumatically Pumped Thermal Storage System". In: 2016 International Conference on Energy Sustainability, North Carolina, USA: ASME, 2016, pp. 59-66.

8. Jianjun Zhu,Banjar, Hattan,Zhenyan Xia., "CFD simulation and experimental study of oil viscosity effect on multi-stage electrical submersible pump (ESP) performance". Petroleum Science and Engineering , 146(7), 2016, pp.735-746.

9. Brook, Graham , Lovick, Jonathon., "System Design and Flow Assurance Implications of Hydraulic Submersible Pumps for Artificial Lift”. In :SPE Annual Caspian Technical Conference and Exhibition, Astana, Kazakhstan : Society of Petroleum Engineers , 2014, pp.12-14.

10. Marsis,Emanuel;Patil,Abhay;Baillargeon,David.et.al., “A State-ofthe-art Modeling Technique for Thrust Prediction in Bottom Hole Electrical Submersible Pumps". In: 2015 SPE Artificial Lift Conference, Bahia, Brazil:Society of Petroleum Engineers, 2015, pp.225-233.
11. Rabbi, S.F. ; Rahman, M.A. ; Sarker, M.M..et.al., "Modeling and Performance Evaluation of a Hysteresis IPM Motor Drive for Electric Submersible Pumps ". In: 7th Annual IEEE Energy Conversion Congress and Exposition, Montreal, Canada: Institute of Electrical and Electronics Engineers Inc, 2015, pp.41054112.

12. Gongliang Zheng, Zhebo Zhou, Man Liu,et al., "Design of Pneumatic Submersible Pumps Automatically Control Structure ". Coal Mine Machinery, 34(11), 2013, pp.155-156.

13. Haizhen Liang., "Research on Speed-Limited Protection Device of Mine Pneumatic Pump". Anhui University of Science \& Technology, 2013, pp.24-35.

14. R.S. Minette; S.F. SilvaNeto,et.al., Monteiro."Experimental modal analysis of electrical submersible pumps". Ocean Engineering, 124, 2016, pp. 168-179.

15. Syuan-Yi Chen; Sheng-Sian Gong., "Speed tracking control of pneumatic motor servo systems using observation-based adaptive dynamic sliding-mode control". Mechanical Systems and Signal Processing,2017, pp.111-128.

16. M O Tokhi; I.N. Reynolds;M. Brisland., "Real-time Control of a Radial Piston Air Motor". IFAC Proceedings Volumes, 15(1), 2002, pp.385-390.

17. Lei Fu; Guojun Li., "Research on product value of wheel diameter and rotational speed - A new design parameter for micro radial turbines". Archives of Civil and Mechanical Engineering, 17(2), 2016, pp.231-239.

18. Qian Zhang, Yuanyang Zhao, Le Wang,et al., "Research Status of Compressed Air System Energy Saving Technology". Fluid Machinery, 44(3), 2016, pp.38-40.

19. Cong Chen, Zhiyi Sun, Yanhong Bai., "Study on Characteristics of Pneumatic Valve-controlled Cylinder System Based on AMESim". Machine Tool \& Hydraulics, 42(19), 2014, pp.34-37.

20. Dai-zong Xiao., "Simulation Technique of AMESim and Its Application in Design and Performance Analysis of Hydraulic Component”. SHIP Science and Technology,29, 2007, pp.142-145. 